\title{
ORIGINAL ARTICLE \\ PATTERN OF CORONARY ARTERY DISEASES IN PATIENTS UNDER 40 YEARS OF AGE WITH ACUTE CORONARY SYNDROME
}

\author{
Iram Jehan Balouch ${ }^{1}$, Iftikhar Ahmed ${ }^{1}$, Faiza Farooq ${ }^{2}$, Syed Ahsan Raza', Najia Aslam \\ Soomro $^{3}$, Muhammad Nauman Khan ${ }^{2}$, Jawaid Akbar Sial' ${ }^{2}$, Musa Karim ${ }^{2}$ \\ ${ }^{1}$ Hyderabad Satellite Center of National Institute of Cardiovascular Disease, Pakistan, ${ }^{1}$ National Institute of Cardiovascular Diseases, \\ Karachi, Pakistan, ${ }^{3}$ Liaquat National Hospital, Karachi, Pakistan
}

\begin{abstract}
Objectives: To determine the pattern of coronary artery diseases (CAD) in patients under 40 years of age with acute coronary syndrome (ACS) presenting at Hyderabad Satellite Center of National Institute of Cardiovascular Disease (NICVD), Pakistan.

Methodology: This cross-sectional study was conducted at cardiology department of the NICVD, Hyderabad Satellite Center. Both male and female patients, between 18 to 40 years of age, diagnosed with acute coronary syndrome (ACS), and undergone coronary angiography were included in this study. Angiographic patterns in terms of extent of the disease (number of diseased vessels and localization of lesion) were assessed.

Results: Total of 220 young patients included. Patients were predominantly male (91.8\%) with the mean age of $35.3 \pm 5$ years. Smoking was observed $30.5 \%$ followed by hypertension $(24.5 \%)$ and positive family history of CAD $(19.1 \%)$. A majority of the patients $(79.1 \%)$ were diagnosed as with ST-elevation myocardial infarction (STEMI) with anterior wall myocardial infarction (MI) as the most common (57.3\%) type of MI. Most of the patients (70\%) had single vessel diseases (SVD) with left anterior descending artery (LAD) as the most commonly diseases vessel (53.6\%). Nine (4.1\%) patients had significant left main disease and $6.4 \%$ had non-obstructive CAD.

Conclusion: The common clinical presentation of ACS in younger patients is STEMI. Smoking is the commonest risk factor followed by hypertension and family history of CAD. More than $2 / 3$ rd of the young patients are expected to have single vessel diseases with LAD as the most commonly diseased vessel.
\end{abstract}

Keywords: STEMI, Acute Coronary Syndrome, Angiography

Citation: Balouch IJ, Ahmed I, Farooq F, Raza SA, Soomro NA, Khan MN, Sial JA, Karim M. Pattern of Coronary Artery Diseases in Patients Under 40 Years of Age with Acute Coronary Syndrome. Pak Heart J. 2021;54(02):144147. DOI: https://doi.org/10.47144/phj.v54i2.2089

\section{INTRODUCTION}

Once considered to be the disease of the old, ischemic heart disease (IHD) in young population, also termed as premature coronary artery disease (CAD), remains a rising public health concern in our society. ${ }^{1}$ The frequency of IHD in South Asian population is more than that of population in the western world. Necropsy studies have demonstrated that atherosclerotic changes initiated in the blood vessels in early life and become symptomatic after 40 years of life. $^{2}$ The increase frequency of cardiovascular disorders in young generation is an alarming public health issue. ${ }^{3}$ In younger patients with IHD, a greater participation of the genetic component has been discussed. ${ }^{4}$ The incidence of younger age group was significantly higher in men compared to women and majority of those sufferings belong to lower middle class socioeconomic structure of the society. ${ }^{5}$ It is unclear that the pathophysiology of myocardial infarction at a young age is same as same observed in older patients. MI is mainly owing to congenital coronary anomaly, coronary spasm, premature atherosclerosis, and drug induced. Some researchers reported that drug induced myocardial infarction is related with atherogenic consequences in young individuals due to long term abuse of drugs. ${ }^{6}$

The data regarding risk factors and coronary angiographic findings in young adults with ACS in Pakistan is limited. Despite the fact that few studies have been carried out in subcontinent there is expected variability in the results in our population due to socioeconomic and cultural diversity. Hence this study was conducted with aim to determine the pattern of CAD in patients under 40 years of age with ACS. The current study aims not only to contribute to the scientific understanding of the disease but also helps in the development of appropriate strategies of screening such patients at an appropriate age so to prevent IHD among young population. 


\section{METHODOLOGY}

This descriptive cross-sectional study was performed at the cardiology department of National Institute of Cardiovascular Disease (NICVD), Hyderabad Satellite Center during January 2020 to June 2020. All patients between the 20-40 years of age were included in this study considering the inclusion and exclusion criteria. Inclusion criteria were both male and female patients, age between 18 to 40 years, diagnosed with acute coronary syndrome (ACS), and undergoing percutaneous coronary intervention (PCI). Exclusion criteria were patient with prior history of ACS, history of any cardiac surgery, or refused to give consent for participation.

Approval of ethical review committee of NICVD was taken prior to the data collection (ERC02/2020). Consecutive patients fulfilling the inclusion/exclusion criteria were included. Prior to inclusion the purpose, and benefits of the study were explained to all participants and verbal informed consent was taken by the principal investigator from all patients regarding their participation in the study and publication of obtained data while maintaining confidentiality.

Demographic detail such as gender and age (years), and history of the patients were taken regarding hypertension, diabetic mellitus, family history, and obesity. A baseline 12-lead electrocardiogram (ECG) was obtained for all the patients and type and location of myocardial infarction was classified. Percutaneous coronary intervention (PCI) was performed in all the patients and angiographic patterns in terms of extent of the disease (number of diseased vessels, localization of diseases and stenosis (\%), left ventricular ejection fraction (LVEF), initial TIMI flow grade, and thrombus grade) and procedural characteristics (use of export, pre balloon used, and tiroflaban infusion, type of stent, and final TIMI flow grade) were recorded. Localization of diseases and stenosis (\%) was assessed as ostial, proximal, mid, or distal for all major coronary arteries namely left main (LM), left anterior descending artery (LAD), left circumflex artery (LCX), right coronary artery (RCA), obtuse marginal (OM), and ramus intermedius.

Data will be entered and analysis using SPSS version-21 (IBM Corp. Released 2012. IBM SPSS Statistics for Windows, Version 21.0. Armonk, NY: IBM Corp). Continuous variables were expressed using descriptive statistics such as mean \pm standard deviation (SD) or median [interquartile range (IQR)] appropriately. Frequency and percentages were calculated for categorical variables.

\section{RESULTS}

A total of 220 young patients between the 20 to 40 years of age were included in this study. Patients were predominantly male $(91.8 \%)$ with the mean age of $35.3 \pm 5$ years. Smoking was found to be the most common (30.5\%) co-morbid followed by hypertension $(24.5 \%)$ and $19.1 \%$ of the patients had positive family history of CAD. A majority of the patients $(79.1 \%)$ were diagnosed with STEMI at presentation with anterior wall MI as the most common $(57.3 \%)$ type of MI. Baseline demographic and clinical characteristics are presented in Table 1.

Table 1: Demographic and Clinical Features

\begin{tabular}{|l|c|}
\hline Characteristics & Total \\
\hline Subjects (N) & 220 \\
\hline Gender & $91.8 \%(202)$ \\
\hline Male & $8.2 \%(18)$ \\
\hline Female & $35.3 \pm 5$ \\
\hline Age (years) & $19.1 \%(42)$ \\
\hline 20 to 30 years & $80.9 \%(178)$ \\
\hline 31 to 40 years & $24.5 \%(54)$ \\
\hline Risk Factors & $9.1 \%(20)$ \\
\hline Hypertension & $30.5 \%(67)$ \\
\hline Diabetes mellitus & $7.7 \%(17)$ \\
\hline Smoking & $3.2 \%(7)$ \\
\hline Obesity & $19.1 \%(42)$ \\
\hline Dyslipidemia & $79.1 \%(174)$ \\
\hline Family history of coronary artery diseases & $20 \%(44)$ \\
\hline Acute coronary syndrome (ACS) & $0.9 \%(2)$ \\
\hline STEMI & $35.5 \%(78)$ \\
\hline NSTEMI & $20.9 \%(46)$ \\
\hline Unstable angina (UA) & $57.3 \%(126)$ \\
\hline Type of myocardial infarction (MI) & $7.7 \%(17)$ \\
\hline Inferior Wall & $3.2 \%(7)$ \\
\hline Posterior Wall & \\
\hline Anterior Wall & \\
\hline Lateral Wall & High Lateral Wall \\
\hline STEMI = ST elevation myocardial infarction, NSTEMI = Non- \\
ST elevation myocardial infarction
\end{tabular}

Table 2: Cardiac Catheterization

\begin{tabular}{|l|c|}
\hline Characteristics & Total \\
\hline Subjects (n) & 220 \\
\hline Vessels involved \\
\hline Single vessel diseased (SVD) & $70 \%(154)$ \\
\hline Two vessels diseased (2VD) & $24.1 \%(53)$ \\
\hline Three vessels diseased (3VD) & $5.9 \%(13)$ \\
\hline Diseased vessels \\
\hline Left main (LM) & $4.1 \%(9)$ \\
\hline $\begin{array}{l}\text { Left anterior descending } \\
\text { artery (LAD) }\end{array}$ & $53.6 \%(118)$ \\
\hline Left circumflex artery (LCX) & $26.4 \%(58)$ \\
\hline Right coronary artery (RCA) & $26.8 \%(59)$ \\
\hline Obtuse marginal (OM) & $0.5 \%(1)$ \\
\hline Ramus intermedius & $1.8 \%(4)$ \\
\hline Non Obstructive & $6.4 \%(14)$ \\
\hline Left ventricular ejection fraction (LVEF) \\
\hline $20-25 \%$ & $4.5 \%(10)$ \\
\hline $25-30 \%$ & $29.1 \%(64)$ \\
\hline $30-35 \%$ & $8.6 \%(19)$ \\
\hline $35-40 \%$ & $6.8 \%(15)$ \\
\hline $40-45 \%$ & $31.8 \%(70)$ \\
\hline $45-50 \%$ & $13.6 \%(30)$ \\
\hline
\end{tabular}




\begin{tabular}{|c|c|}
\hline $50 \%+$ & $5.5 \%(12)$ \\
\hline \multicolumn{2}{|c|}{$\begin{array}{l}\text { Initial thrombolysis in myocardial infarction (TIMI) flow } \\
\text { grade }\end{array}$} \\
\hline 0 & $33.6 \%(74)$ \\
\hline I & $25 \%(55)$ \\
\hline II & $23.6 \%(52)$ \\
\hline III & $17.7 \%(39)$ \\
\hline \multicolumn{2}{|l|}{ Thrombus Grade } \\
\hline 0 & $5.9 \%(13)$ \\
\hline I & $3.2 \%(7)$ \\
\hline II & $15.5 \%(34)$ \\
\hline III & $12.7 \%(28)$ \\
\hline IV & $33.6 \%(74)$ \\
\hline $\mathrm{V}$ & $29.1 \%(64)$ \\
\hline Export used & $45.5 \%(100)$ \\
\hline Pre balloon used & $45 \%(99)$ \\
\hline \multicolumn{2}{|l|}{ Type of stent } \\
\hline Drug-eluting stents (DES) & $86.4 \%(190)$ \\
\hline Bare-metal stent (BMS) & $10.9 \%(24)$ \\
\hline Plain old balloon angioplasty & $2.7 \%(6)$ \\
\hline Tiroflaban Infusion & $47.7 \%(105)$ \\
\hline \multicolumn{2}{|l|}{ Final TIMI flow grade } \\
\hline 0 & $0.9 \%(2)$ \\
\hline
\end{tabular}

\begin{tabular}{|l|c|}
\hline I & $6.4 \%(14)$ \\
\hline II & $54.5 \%(120)$ \\
\hline III & $38.2 \%(84)$ \\
\hline
\end{tabular}

Most of the patients $(70 \%)$ had single vessel coronary artery diseases with LAD as the most commonly diseases vessel $(53.6 \%)$ followed by RCA (26.8\%), and LCX (26.4\%). Nine (4.1\%) patients had significant left main disease and $6.4 \%$ had non-obstructive coronary artery diseases. In this cohort we observed a significant thrombus burden with thrombus grade $\mathrm{V}$ in $29.1 \%$ and IV in $33.6 \%$ of the patients. Export was used in $45.5 \%$ of the patients, DES was deployed in $86.4 \%$, and final TIMI flow grade II-III was observed in $92.7 \%$ of the patients. Characteristics and finding of cardiac catheterization are presented in Table 2 . Distribution of localization of disease is presented in Table 3.

\section{Table 3: Localization of Diseases}

\begin{tabular}{|l|c|c|c|c|c|c|}
\hline & LM & LAD & LCX & RCA & OM & RAMUS \\
\hline Total (N) & $\mathbf{9}$ & $\mathbf{1 1 8}$ & $\mathbf{5 8}$ & $\mathbf{5 9}$ & $\mathbf{1}$ & $\mathbf{4}$ \\
\hline Stenosis (\%) & $56.7 \pm 13.2$ & $92 \pm 7.4$ & $85.2 \pm 9.1$ & $92.1 \pm 8.4$ & $100 \pm 0$ & $90 \pm 8.2$ \\
\hline Characteristics & & & & & \\
\hline Ostial & $0(0 \%)$ & $25(21.2 \%)$ & $2(3.4 \%)$ & $3(5.1 \%)$ & $0(0 \%)$ & $0(0 \%)$ \\
\hline Proximal & $0(0 \%)$ & $48(40.7 \%)$ & $14(24.1 \%)$ & $31(52.5 \%)$ & $1(100 \%)$ & $4(100 \%)$ \\
\hline Mid & $0(0 \%)$ & $48(40.7 \%)$ & $42(72.4 \%)$ & $22(37.3 \%)$ & $0(0 \%)$ & $0(0 \%)$ \\
\hline Distal & $9(100 \%)$ & $4(3.4 \%)$ & $0(0 \%)$ & $1(1.7 \%)$ & $0(0 \%)$ & $0(0 \%)$ \\
\hline
\end{tabular}

$L M=$ left main, $L A D=$ left anterior descending artery, $L C X=$ left circumflex artery, $R C A=$ right coronary artery, OM $=$ obtuse marginal, RAMUS = ramus intermedius

\section{DISCUSSION}

ACS in young adults has to be taken as a serious public health issue in Pakistan, more efforts and resources are needed to understand the development and progression CVD in this population. Therefore, in present study our aim was to evaluate the pattern of CAD in young $(\leq 40$ years) patients presented with ACS. Patients were predominantly male with smoking as a most common conventional risk factor followed by hypertension and positive family history of CAD. More than $2 / 3 \mathrm{rd}$ of the patients had single vessel diseases (SVD) with LAD as the most commonly diseased vessel followed by RCA, and LCX and around $80 \%$ of them were diagnosed with ST-segment elevation myocardial infarction (STEMI) at presentation. Significant left main disease was not that common observed in about $4.1 \%$ of the patients and a significant thrombus burden was observed with thrombus grade IV or higher in more than $60 \%$ of the patients.

The MI is more common in South Asian populations as compared to the western population and the South Asians, are unduly prone to develop CAD in young patients. $^{7-9}$ The clinical proportion of premature $\mathrm{MI}$ is reported to be $2-12 \%$ of total STEMI.,10,11 Some ACS studies reported similar male predominance in younger patients with CVD. ${ }^{12,13} \mathrm{CAD}$ is less common in premenopausal women due to the protective effects of estrogen but the risk is enhancing in menopause. ${ }^{14}$ In general, various risk factors are considered to play a significant role in development of $\mathrm{CAD}$ is younger adults. We have observed that smoking, hypertension, family history of CAD were the leading conventional risk factors in this population, while, other conventional risk factors such as diabetes, obesity, and dyslipidemia were not that common. Similar to our study various studies in the past have highlighted sedentary lifestyle, smoking, and positive family history as a key risk factors of CAD is younger population. ${ }^{13,15-17}$ A recent study by Ahmed $\mathrm{S}$ et al. ${ }^{18}$ compared outcomes of primary PCI in young smokers and non-smoker patients without any other conventional risk factors of CAD and reported no significant differences in disease pattern and immediate clinical outcomes after primary PCI. Further they argued the need of understanding and identification of risk factors other than conventional risk factors and timely risk stratification in these patients. Similarly, Ashraf T et al. ${ }^{19}$ also highlighted need of a population-specific risk stratification system for primary prevention in this population.

Multivessel disease (MVD) was less common in young patients, it account for only about $1 / 3$ rd of the total patients, which was smaller than some of the past studies on STEMI patients in Pakistani population. Muhammad AS et al. ${ }^{20}$ reported MVD in $40.1 \%$ of the patients with STEMI under 45 years of age. Similarly, in a study by 
Batra MK et al. ${ }^{1}$ MVD was reported in $38 \%$ of young ( $\leq$ 40 years) patients with STEMI. The proportion of MVD in young patients is reported to be ranging from 16 to $56 \%$ in studies conducted in various populations of the world. $^{21-25}$

A single center non-comparative study are the key limitation of this study. Further studies are needed to identify risk factors, in addition to the conventional risk factors of CAD, aggravating the cardiovascular diseases in young population.

\section{CONCLUSION}

The common clinical presentation of ACS in younger patients is STEMI. Smoking is the commonest risk factor followed by hypertension and family history of CAD. More than $2 / 3^{\text {rd }}$ of the young patients are expected to have single vessel diseases with LAD as the most commonly diseased vessel followed by RCA, and LCX.

AUTHORS' CONTRIBUTION: IJB: Concept and design, data acquisition, interpretation, drafting, final approval, and agree to be accountable for all aspects of the work. IA, FF, SAR, NAS, MNK, JAS, MK: Data acquisition, interpretation, drafting, final approval and agree to be accountable for all aspects of the work.

Conflict of interest: Authors declared no conflict of interest.

\section{REFERENCES}

1. Batra MK, Rizvi NH, Sial JA, Saghir T, Karim M. Angiographic characteristics and in hospital outcome of young patients, age up to 40 versus more than 40 years undergoing primary percutaneous coronary intervention. J Pak Med Assoc. 2019;69(9):1308-12.

2. Tuzcu EM, Kapadia SR, Tutar E, Ziada KM, Hobbs RE, McCarthy PM, et al. High prevalence of coronary atherosclerosis in asymptomatic teenagers and young adults: evidence from intravascular ultrasound. Circulation. 2001;103(22):2705-10.

3. Bonow RO, Smaha LA, Smith Jr SC, Mensah GA, Lenfant C. World Heart Day 2002: the international burden of cardiovascular disease: responding to the emerging global epidemic. Circulation. 2002;106(13):1602-5.

4. Mansur AdP, Mattar AP, Rolim AL, Yoshi FR, Marin JF, César LAM, et al. Distribution of risk factors in parents and siblings of patients with early coronary artery disease. Arq Bras Cardiol. 2003;80(6):582-4.

5. Cheng C-I, Yeh K-H, Chang H-W, Yu T-H, Chen Y-H, Chai H$\mathrm{T}$, et al. Comparison of baseline characteristics, clinical features, angiographic results, and early outcomes in men vs women with acute myocardial infarction undergoing primary coronary intervention. Chest. 2004;126(1):47-53.

6. Zimmerman F, Cameron A, Fisher L, Ng G. Myocardial infarction in young adults: angiographic characterization, risk factors and prognosis (Coronary Artery Surgery Study Registry). J Am Coll Cardiol. 1995;26(3):654.

7. Sharma M, Ganguly NK. Premature coronary artery disease in Indians and its associated risk factors. Vasc Health Risk Manag 2005;1(3):217.

Address for Correspondence:

Dr. Iram Jehan Balouch, Assistant Professor at National Institute of Cardiovascular Disease, Hyderabad, Pakistan. Email: drebalouch@gmail.com
8. Joshi P, Islam S, Pais P, Reddy S, Dorairaj P, Kazmi K, et al. Risk factors for early myocardial infarction in South Asians compared with individuals in other countries. JAMA. 2007;297(3):286-94.

9. Islam AM, Majumder A. Coronary artery disease in Bangladesh: A review. Indian Heart J. 2013;65(4):424-35.

10. Rallidis LS, Pavlakis G. The fundamental importance of smoking cessation in those with premature ST-segment elevation acute myocardial infarction. Curr Opin Cardiol. 2016;31(5):531-6.

11. Singh B, Singh A, Goyal A, Chhabra S, Tandon R, Aslam N, et al. The prevalence, clinical spectrum and the long term outcome of ST-segment elevation myocardial infarction in young-a prospective observational study. Cardiovasc Revasc Med. 2019;20(5):387-91.

12. El-Menyar A, Ahmed E, Albinali H, Al-Thani H, Gehani A, Singh $\mathrm{R}$, et al. Mortality trends in women and men presenting with acute coronary syndrome: insights from a 20 -year registry. PLoS One. 2013;8(7):e70066.

13. Puricel S, Lehner C, Oberhänsli M, Rutz T, Togni M, Stadelmann $\mathrm{M}$, et al. Acute coronary syndrome in patients younger than 30 years--aetiologies, baseline characteristics and long-term clinical outcome. Swiss Med Wkly. 2013;143:w13816.

14. Maas AH, Appelman YE. Gender differences in coronary heart disease. Neth Heart J. 2010;18(12):598-603.

15. Schoenenberger AW, Radovanovic D, Stauffer J-C, Windecker S, Urban P, Niedermaier G, et al. Acute coronary syndromes in young patients: presentation, treatment and outcome. Int J Cardiol. 2011;148(3):300-4.

16. Nadeem M, Ahmed SS, Mansoor S, Farooq S. Risk factors for coronary heart disease in patients below 45 years of age. Pak J Med Sci. 2013;29(1):91.

17. Rallidis LS, Pavlakis G, Foscolou A, Kotakos C, Katsimardos A, Drosatos A, et al. High levels of lipoprotein (a) and premature acute coronary syndrome. Atherosclerosis. 2018;269:29-34.

18. Ahmed S, Khowaja S, Khowaja S, Ashraf T, Aamir K, Batra MK, et al. Differences in angiographic profile and immediate outcome of primary percutaneous coronary intervention in otherwise riskfree young male smokers. Cureus. 2020;12(6).

19. Ashraf T, Mengal MN, Muhammad AS, Tareen AK, Khan MN, Kazmi KA, et al. Ten years risk assessment of atherosclerotic cardiovascular disease using Astro-CHARM and pooled cohort equation in a south Asian sub-population. BMC Public Health. 2020;20:1-6

20. Muhammad AS, Ashraf T, Mir A, Alishan S, Farooq F, Ammar A, et al. Comparative assessment of clinical profile and outcomes after primary percutaneous coronary intervention in young patients with single vs multivessel disease. World J Cardiol. 2020;12(4):136.

21. Esteban MR, Montero SM, Sánchez JJ, Hernández HP, Pérez JJ, Afonso $\mathrm{JH}$. Acute coronary syndrome in the young: clinical characteristics, risk factors and prognosis. Open Cardiovasc Med J. 2014;8:61

22. Deora S, Kumar T, Ramalingam R, Manjunath CN. Demographic and angiographic profile in premature cases of acute coronary syndrome: analysis of 820 young patients from South India. Cardiovasc Diagn Ther. 2016;6(3):193.

23. Waziri H, Jørgensen E, Kelbæk H, Stagmo M, Pedersen F, Lagerqvist B, et al. Short and long-term survival after primary percutaneous coronary intervention in young patients with STelevation myocardial infarction. Int J Cardiol. 2016;203:697-701.

24. Ge J, Li J, Yu H, Hou B. Hypertension Is an Independent Predictor of Multivessel Coronary Artery Disease in Young Adults with Acute Coronary Syndrome. Int J Hypertens. 2018;2018.

25. Anjum M, Zaman M, Ullah F. Are Their Young Coronaries Old Enough? Angiographic Findings In Young Patients With Acute Myocardial Infarction. J Ayub Med Coll Abbottabad. 2019;31(2):151-5. 